\title{
Wireless Sensor Network-Based Monitoring of Bridge Pile Foundations for Detecting Scouring Depth
}

\author{
Han-Tang Huang \\ Department of Civil Engineering, National Taiwan University, Taipei, 10617, Taiwan \\ H. Ping Tserng \\ Department of Civil Engineering, National Taiwan University, Taipei, 10617, Taiwan \\ Ruei-Yu Hou \\ Department of Civil Engineering, National Taiwan University, Taipei, 10617, Taiwan \\ Mirosław Skibniewski \\ Dept. of Civil \& Env. Engineering, University of Maryland, College Park, USA
}

Follow this and additional works at: https://jmstt.ntou.edu.tw/journal

Part of the Fresh Water Studies Commons, Marine Biology Commons, Ocean Engineering Commons, Oceanography Commons, and the Other Oceanography and Atmospheric Sciences and Meteorology Commons

\section{Recommended Citation}

Huang, Han-Tang; Tserng, H. Ping; Hou, Ruei-Yu; and Skibniewski, Mirosław (2021) "Wireless Sensor Network-Based Monitoring of Bridge Pile Foundations for Detecting Scouring Depth," Journal of Marine Science and Technology. Vol. 29: Iss. 1, Article 6. DOI: $10.51400 / 2709-6998.1005$

Available at: https://jmstt.ntou.edu.tw/journal/vol29/iss1/6

This Research Article is brought to you for free and open access by Journal of Marine Science and Technology. It has been accepted for inclusion in Journal of Marine Science and Technology by an authorized editor of Journal of Marine Science and Technology. 


\title{
Wireless Sensor Network-Based Monitoring of Bridge Pile Foundations for Detecting Scouring Depth
}

\author{
Han-Tang Huang ${ }^{a}$, H. Ping Tserng ${ }^{a}$,, Ruei-Yu Hou ${ }^{a}$, Mirosław Skibniewski ${ }^{\text {b,c,d,e,f }}$ \\ ${ }^{\text {a }}$ Department of Civil Engineering, National Taiwan University, Taipei, 10617, Taiwan \\ ${ }^{\mathrm{b}}$ Dept. of Civil \& Env. Engineering, University of Maryland, College Park, USA \\ ${ }^{\mathrm{c}}$ Institute for Theoretical and Applied Informatics, Polish Academy of Sciences, Gliwice, Poland \\ ${ }^{\mathrm{d}}$ Chaoyang University of Technology, Taichung, Taiwan \\ ${ }^{\mathrm{e}}$ Dept. of Civil and Env. Engineering \& Architecture, UTP University of Science and Technology, Bydgoszcz, Poland \\ ${ }^{\mathrm{f}}$ Dept. of Civil and Architectural Engineering, Aarhus University, Denmark
}

\begin{abstract}
Climate change brings about unprecedented increases in the occurrence of storms and flooding. In response to increased risk of bridge pier scouring, there is a need for increased safety monitoring of bridges. This paper presents a wireless sensor network (WSN) - based solution developed to measure micro-vibrations of a bridge pier. Test measurement values are converted with the use of the Fast Fourier Transform (FFT) method to obtain natural frequencies. Scouring depth of the pier is estimated with the use of a Finite Element Method model. WSN is used to collect the signal and to test data transmission stability in different locations, as well as FFT and Welch method are used to convert the obtained signal into spectral signals allows an automatic determination and storage of pier vibration frequency data. Relevant parameters in a Finite Element Method (FEM) model use the in-situ natural frequencies as calibration parameters, and the soil equivalent spring model was set up by using in-situ drilling data. The maximum spring depth represents the depth of the scouring. The scouring depth and natural frequency data are used as follow-up indicators of bridge scouring condition. WSN is used to monitor condition of piers provides a practical method and tool for mitigating potential bridge collapse.
\end{abstract}

Keywords: Bridge scouring, Structural health diagnosis, Wireless sensor network, Micro-vibration test, Bridge monitoring

\section{Introduction}

$I^{n}$ $\mathrm{n}$ recent years, due to abnormal weather conditions, rainfall has dramatically changed, which leads to the floods continuously scouring bridge piers, causing severe damage. Local scour arises from the increased velocities and associated vortices and remove of material from around Bridge piers as water accelerates around the corners of the bridge pile. In this study, Yi-Shou Bridge pile is belonged to local scour. Bridge safety is an issue that concerns not only the government but also the general populace. The existing bridge monitoring system is still mainly based on wired transmission, and the pipeline setting cost increases as the length of the bridge increases. How to monitor the change of scouring depth of bridge piers is an important issue needed to be solved.

This study conducts a micro-vibrating test on the bridge using accelerator combined with the Wireless Sensor Network (WSN) system. The monitoring data is applied to Fast Fourier Transform (FFT)to output the natural frequency of the bridge. Then the scouring depth is estimated through the output data and the finite element model. A lot of existing WSN and bridge structural safety monitoring researches

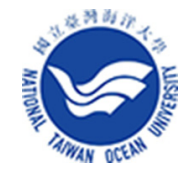


Table 1. Effect of scouring on natural frequency thesis literature.

\begin{tabular}{|c|c|c|c|}
\hline years & Researching topic & Researching methods & Researching results \\
\hline 2008 & $\begin{array}{l}\text { A Modified Procedure for } \\
\text { Determining Structure } \\
\text { Frequency of A Bridge. } \\
\text { [1] }\end{array}$ & $\begin{array}{l}\text { Micro-Vibration test, } \\
\text { Finite Element Method }\end{array}$ & $\begin{array}{l}\text { Using different concrete strength, beam conditions } \\
\text { combination, compared to the in-situ measurement } \\
\text { results. }\end{array}$ \\
\hline 2011 & $\begin{array}{l}\text { Field Scour Simulation and } \\
\text { Dynamic Test of a Bridge. } \\
\text { [2] }\end{array}$ & $\begin{array}{l}\text { Micro-Vibration experiment, } \\
\text { Cap impact test, scouring test }\end{array}$ & $\begin{array}{l}\text { Scouring simulation of the digged } 1.5 \mathrm{~m} \text { pier foundation } \\
\text { and } 3 \mathrm{~m} \text { bridge. Put the speedometer on the piers and } \\
\text { measure, and then explore the change of the pier } \\
\text { frequency. }\end{array}$ \\
\hline 2011 & $\begin{array}{l}\text { Investigation of Soil-Bridge } \\
\text { Interaction Analyses for Bridge } \\
\text { Scour. } \\
\text { [3] }\end{array}$ & $\begin{array}{l}\text { Micro-Vibration test, Finite } \\
\text { Element Method }\end{array}$ & $\begin{array}{l}\text { Measuring } 10 \text { existing bridges. Explore the influence of } \\
\text { scouring depth and soil properties on the natural } \\
\text { vibration frequency by model. }\end{array}$ \\
\hline 2012 & $\begin{array}{l}\text { A Study on the Feasibility of } \\
\text { Identifying the Exposure of a } \\
\text { Bridge Pier Foundation by Using } \\
\text { It's Natural Frequencies. } \\
\text { [4] }\end{array}$ & $\begin{array}{l}\text { Micro-Vibration test, free } \\
\text { vibration, System identification }\end{array}$ & $\begin{array}{l}\text { Test the behaviors of different soil equivalent spring } \\
\text { conditions by ARV(Auto-Regressive Vector)and ARX } \\
\text { (Auto regressive model). }\end{array}$ \\
\hline 2012 & $\begin{array}{l}\text { A preliminary study of using the } \\
\text { pier vibration frequency to } \\
\text { evaluate the bridge safety. } \\
\text { [5] }\end{array}$ & Finite Element Method & $\begin{array}{l}\text { Pushover Analysis } \\
\text { Analyze the frequency difference before and after the } \\
\text { damage of the bridge by pushover analysis and } \\
\text { structural capacity to simulate Yilan zhi-xin bridge as } \\
\text { example. }\end{array}$ \\
\hline 2013 & $\begin{array}{l}\text { Identification of foundation scour } \\
\text { depth using bridge natural } \\
\text { frequencies. } \\
\text { [6] }\end{array}$ & $\begin{array}{l}\text { Finite Element Method, Simple } \\
\text { Element Method }\end{array}$ & $\begin{array}{l}\text { Compare roller and Spring as the calculation of soil } \\
\text { bundles and find out that there is no significant } \\
\text { difference. Propose bigger change in the frequency of } \\
\text { the deeper scouring depth. }\end{array}$ \\
\hline
\end{tabular}

do not discuss limitations on and potential improvement for developing the overall system; additionally, most of this research is paid for by private companies. Therefore, this study not only focuses on establishing the method of bridge structure surveying, but also spares no efforts on how to use the device with open-source technology to develop the WSN system.

The purpose of this research was to develop a bridge monitoring system based on an open-source WSN system. Then, a specific bridge was chosen to conduct a field test to ensure stability on transmission of the system. The followings were objectives of this study:

1. Establishing a process to develop the WSN system, which includes a method of correction in the lab, limitations on the transmission and monitoring process during a field test, and setup of an automatic monitoring process.

2. Renewing the existing finite element model based on the natural frequency of the bridge acquired from survey data, and then estimating the change of the natural frequency under a different scouring depth as the basis for monitoring the current safety status of the bridge.

\section{Literature review}

The recent studies show that pier scouring will affect the natural frequency, which declines when scouring depth is increased, and the Finite Element Method can simulate this change. Then the current natural frequency of bridge obtained by the appropriate sensing equipment can be obtained as the basis for model correction. Related thesis literature is organized in Table 1, and journal articles are organized in Table 2.

Base on the installed location of equipment, safety monitoring of bridges can be divided into two categories: "Installed on the bridge deck" or "Installed under the bridge deck" according to Tables 1 and 2, which are researches about the influence of scouring to natural frequency, we can see most research put equipment under the bridge deck, except a preliminary study of using the pier vibration frequency to evaluate the bridge safety. The monitoring equipment installed on the bridge are easy to be destroyed by typhoon, and the function of immediate monitoring can be lost. Common to all the research is that monitoring instrument needs wire connection, while the arrangement needs on-site installation, which makes basic installation difficult, time consuming and safe concern. Therefore, the installation of wired 
Table 2. Effect of scouring on natural frequency journal articles.

\begin{tabular}{|c|c|c|c|}
\hline years & Research topic & Research methods & Research results \\
\hline 2010 & $\begin{array}{l}\text { Artificial neural network study of } \\
\text { observed pattern of scour depth around } \\
\text { bridge piers. } \\
\text { [7] }\end{array}$ & $\begin{array}{l}\text { Artificial neural network (ANN)、In- } \\
\text { situ test }\end{array}$ & $\begin{array}{l}\text { After measuring the total of } 56 \text { bridges at } \\
380 \text { points, make the correlation coefficient } \\
\text { between the model and the scouring depth } \\
\text { up to } 0.81 \text { by using the width, shape, water } \\
\text { depth and water flow velocity as input. }\end{array}$ \\
\hline 2012 & $\begin{array}{l}\text { Wavelet based multi-step filtering } \\
\text { method for bridge health monitoring } \\
\text { using GPS and accelerometer. }\end{array}$ & $\begin{array}{l}\text { Global } \\
\text { Positioning System (GPS) }\end{array}$ & $\begin{array}{l}\text { Experimental results showed that the } \\
\text { frequencies and absolute displacements of } \\
\text { the bridge can be accurate extracted by the } \\
\text { proposed method }\end{array}$ \\
\hline 2012 & $\begin{array}{l}\text { A modified monkey algorithm for } \\
\text { optimal sensor placement in structural } \\
\text { health monitoring. }\end{array}$ & modified monkey algorithm (MA) & $\begin{array}{l}\text { MA proposed could improve the } \\
\text { convergence of the algorithm and the } \\
\text { method is effective in solving } \\
\text { combinatorial optimization problems such } \\
\text { as optimal sensor placement. }\end{array}$ \\
\hline 2013 & $\begin{array}{l}\text { An investigation of the changes in the } \\
\text { natural frequency of a pile affected by } \\
\text { scour. } \\
{[8]}\end{array}$ & $\begin{array}{l}\text { Micro-Vibration test, Finite Element } \\
\text { Method, Scale model }\end{array}$ & $\begin{array}{l}\text { Using the experimental and different } \\
\text { methods of calculating the bundle } \\
\text { conditions (CPT、API、Shear wave), } \\
\text { compare their response ability to natural } \\
\text { frequency. }\end{array}$ \\
\hline 2014 & $\begin{array}{l}\text { A review of bridge scour monitoring } \\
\text { techniques. Prendergast, [9] }\end{array}$ & Detection Review & $\begin{array}{l}\text { Sort out the six major categories of bridge } \\
\text { scouring detecting equipment. }\end{array}$ \\
\hline 2014 & $\begin{array}{l}\text { Hybrid computational model for } \\
\text { predicting bridge scour depth near } \\
\text { piers and abutments. [10] }\end{array}$ & $\begin{array}{l}\text { genetic algorithm (GA)-based support } \\
\text { vector regression (SVR) model }\end{array}$ & $\begin{array}{l}\text { The proposed hybrid model achieved error } \\
\text { rates that were } 81.3 \%-96.4 \% \text { more accurate } \\
\text { than those obtained using other methods. }\end{array}$ \\
\hline 2015 & $\begin{array}{l}\text { Processing of Signals Produced by } \\
\text { Strain Gauges in Testing } \\
\text { Measurements of the Bridges. } \\
{[11]}\end{array}$ & $\begin{array}{l}\text { Micro-Vibration test, Finite Element } \\
\text { Method }\end{array}$ & $\begin{array}{l}\text { The natural frequency of the bridges } \\
\text { estimated by the strain meter is consistent } \\
\text { with the results of the structural model. }\end{array}$ \\
\hline
\end{tabular}

2017 Development of a real-time scour monitoring system for bridge safety evaluation.

[12]

2017 Critical insights for advanced bridge scour detection using the natural frequency.

[13]

2018 New Representative Temperature for Performance

Alarming of Bridge Expansion Joints through Temperature-Displacement Relationship [14]

Micro-Vibration test, Scale model

The frequency measured by the superstructure is divided into the reference group and the rigid body motion group, and the latter is used as the basis for the immediate judgment of bridge safety

Finite Element Method, Scale model The symmetry of scouring shape will affect the main natural frequency of bridge.

temperature-displacement relationship (TDR)

Modal analysis and finite element model updating techniques
The results demonstrate that the proposed approach is superior to traditional ones in terms of modeling and prediction capabilities and is excellent for performance alarming of bridge expansion joints.

Updated finite element model for this structure provides valuable information for bridge condition assessment and proves how structural identification is a viable tool for the case considered. instruments and equipment in order to implement safety monitoring of bridges, is not appropriate to use in Taiwan. This study emphasizes that installation on the bridge deck is less affected by typhoons, that research combine "measurement equipment" and "wireless transmission equipment" in one box. We'll place the box on the bridge deck when doing the measurement. The method above will have the benefits of rapidly, safely and easily installation for safety monitoring of bridges.

\section{Wireless sensor system development}

Due to the benefit of using open-source materials, this research integrated an Arduino board, a boost module, an analog to digital converter (ADC) and an accelerometer into an apparatus, using it to measure the natural frequency of bridges. By processing the collected data, one could infer the current structural status of the bridge. Followings are sections discussing the design of the wireless sensor nodes, the 
Table 3. Arduino UNO Hardware specifications [16].

\begin{tabular}{ll}
\hline Interfaces number & Arduino UNO \\
\hline Microcontrollers & ATmega328 \\
Operating Voltage & $5 \mathrm{~V}$ \\
Input voltage & $7-12 \mathrm{~V}(6-20 \mathrm{~V}$ limited) \\
Digital feet input/output (I/O Pins) & 14 \\
analog feet input/output (I/O Pins) & 6 \\
I/O pin DC Current & $40 \mathrm{~mA}$ \\
3.3 V pin DC Current & $50 \mathrm{~mA}$ \\
Flash 32 KB & $0.5 \mathrm{~KB}$ is bootloader \\
SRAM & $2 \mathrm{~KB}$ \\
EEPROM & $1 \mathrm{~KB}$ \\
Clocks & $16 \mathrm{MHz}$ \\
\hline
\end{tabular}

Table 4. XBee specifications (Digi International, 2016).

\begin{tabular}{ll}
\hline Operating Voltage & $2.8-3.4 \mathrm{~V}$ \\
\hline feet & $\begin{array}{l}20 \text { feet } \\
\text { (9 digit I/O and } 5 \text { digit/ } \\
\text { analog input feet) }\end{array}$ \\
& $2.0 \mathrm{~mm}$ \\
Pin space & $30 \mathrm{~m} \mathrm{(XBee} \mathrm{Pro:90} \mathrm{m)}$ \\
$\begin{array}{l}\text { Indoor transmission distance } \\
\text { Outdoor transmission distance } \\
\text { (no shelter) }\end{array}$ & $100 \mathrm{~m} \mathrm{(XBee} \mathrm{Pro:1200} \mathrm{m)}$ \\
$\begin{array}{l}\text { Wireless operating frequency } \\
\text { Wireless transmission of data } \\
\text { rates }\end{array}$ & $2.4 \mathrm{GHz}$ \\
\hline
\end{tabular}

development of the signal analyzing system, and the systematic process.

\subsection{Development of the wireless sensor device}

This research utilized Arduino board due to its open-source characteristic, along with Digi developed XBee radio module, Texas Instruments developed ADC and boost module. Followings are contents of device's software, hardware and firmware.

\subsubsection{Control board}

This research employed an Arduino UNO as the control board in Table 3, which was equipped with an Atmel AVR microcontroller as the Central Processing Unit (CPU). Because it is open-source, an abundance of software packages, databases and

\begin{tabular}{ll} 
Table 5. ADS-1115 specifications [17] https://wwww.silicondesigns.com/). \\
\hline Size & $2 \mathrm{~mm} \times 1.5 \mathrm{~mm} \times 0.4 \mathrm{~mm}$ \\
\hline Supply Range & $2.0 \mathrm{~V}-5.5 \mathrm{~V}$ \\
Low Current Consumption & $\begin{array}{l}150 \mu \mathrm{A} \\
\text { (Continuous-Conversion Mode) }\end{array}$ \\
Programmable Data Rate & 8 SPS to 860 SPS \\
I2C Interface & Four Pin-Selectable Addresses \\
Operating Temperature Range & $-40{ }^{\circ} \mathrm{C}$ to $+125{ }^{\circ} \mathrm{C}$ \\
\hline
\end{tabular}

interfacing hardware can be easily found online, and therefore this board was convenient to develop, modify, and operate.

\section{- Power handling:}

The power source unit provides electricity to all the units (accelerometer, XBee radio modules, ATMEGA328P) connected to the board including the board itself. Nonetheless, the voltages needed by the accelerometer, radio module and ATMEGA328P are different, thus we used a boost module, directly boosting the power source. We connect the UNO board and the accelerometer in parallel. Therefore, the accelerometer that needs higher voltage will receive the boosted current, and the voltage of the current that flows into the UNO board that runs under a lower voltage will be reduced for other units to operate.

\section{- Signal processing}

Signals returned from the sensors are analog, thus we connected the sensors to the analog pins on the UNO board. After the signals are transmitted to the ATMEGA328P's built-in ADC, the ADC's 10-bit resolution will result in dividing the $5 \mathrm{~V}$ into 1024 segments. Yet the 1024 segments digital signal is not sufficient to reflect the vibration state of the bridge, so we ushered in a 16-bit ADC to raise the precision of our measurement.

\section{- Logical processing}

While transmitting the packet, one must format the data in a specific fashion to "pack" the data into a packet, and "unpack" the packet while receiving it. The ATMEGA328P's microcontroller is in charge of this task. After a series of trials, we found that the most stable outcome is measured when the sampling frequency is set to $30 \mathrm{~Hz}$. Thus, in this research we set $30 \mathrm{~Hz}$ as our sampling frequency. If one seeks higher frequency, one can substitute the UNO with a board that comes with better calculated ability (in other words, a board with a higher spec CPU).

\subsubsection{Transfer module}

This research utilized the Digi-developed XBee radio module in Table 4, which uses Zigbee (IEEE.802.15.4) as its communication protocol. This research deployed the sensors in a mesh topology network. The XBee radio module comes in 2 versions: Series 1 and Series 2. The major difference between them is that Series 1 only provides the 

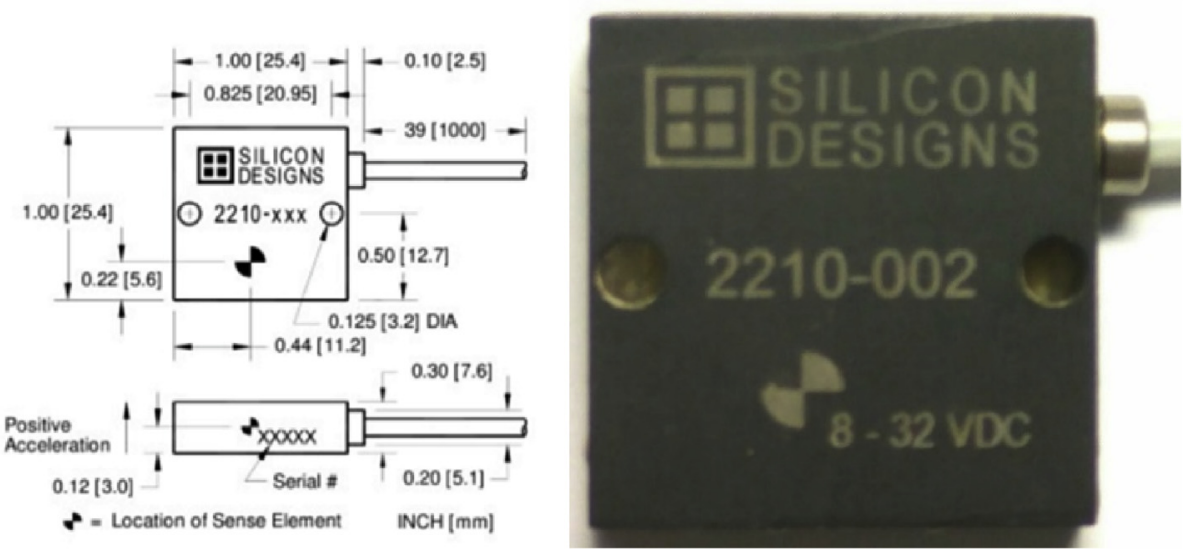

Fig. 1. SD-2210 appearance specifications [18].

ability to transmit data one-to-one between the modules, whereas Series 2 can accomplish one-tomany data transmission. Series 2 is a better option for our mesh network considering we need the nodes to communicate between other multiple nodes. In addition, we adopted both XBee $(100 \mathrm{~m})$ and XBee Pro $(1200 \mathrm{~m})$ to test out the transmission distance.

There are 2 ways to transmit data using XBee: Application Transparent (AT) mode and Application Programming Interface (API) mode. The former transmits the data separately and individually. For example, while transmitting the number 25 , the radio module will send the binary values of 2 and 5 individually to another XBee. Though transmitting in this fashion is faster, it is impossible to check whether part of the data is lost during transmission, and therefore data discontinuity occurs more frequently. API mode, on the other hand, transmits via sending packets, the mechanism prevents part of the data being lost during transmissions, and it prevents the congestion caused by an insufficient buffer in the UNO board. Based on these reasons, this research chose API mode to be the transmission mode.

\subsubsection{Analog to digital converter}

Because the Arduino UNO board's resolution is only 10-bit, not enough to reflect the actual vibration

Table 6. SD-2210 accelerometer specification [18].

\begin{tabular}{ll}
\hline Sensitivity $(\mathrm{mV} / \mathrm{g})$ & 2000 \\
\hline Frequency $(\mathrm{Hz})$ & $0-300$ \\
Acceleration $(\mathrm{g})$ & \pm 2 \\
Noise density $(\mu \mathrm{g} /$ & 13 \\
$\quad \sqrt{\mathrm{Hz}})$ & \\
Output (Volt) & $0.5-4.5$ \\
\hline
\end{tabular}

state, this research employed the ADS-1115 analog to digital converter, made by Texas Instruments in Table 5 . The resolution is 16 -bit, which can divide the analog signal into 65536 (216) segments of digital signal, thus considerably increasing the resolution.

\subsubsection{Accelerometer}

This research used a Silicon Design Model 2210 as the accelerometer (shown for SD-2210 for the remaining materials). As shown in Fig. 1, SD-2210 is a single axis MEMS variable capacitive accelerometer. Although the components have been waterproof-encapsulated, we still placed it in a waterproof box for added security.

The sensitivity of the SD-2210 is $2000 \mathrm{mV} / \mathrm{g}$. In other words, the range covers $-2 \mathrm{~g}-2 \mathrm{~g}$, which is able to measure microseism. The module has 4 wires, 2 of which are an input wire and a ground wire, while the other 2 are positive and negative output wire (both are 5-core wires). Inputting voltage is allowed between $9 \mathrm{~V}$ and $12 \mathrm{~V}$, and the range of output voltages is $0.5 \mathrm{~V}-4.5 \mathrm{~V}$ (Table 6). We can detect each output voltage of $2.5 \mathrm{~V}$ by placing the SD-2210 upright (voltage differences being 0 ), while facing the accelerometer upward or downward will generate 2 $\mathrm{V}$ of voltage difference. As shown in Fig. 2.



Fig. 2. SD-2210 accelerometer calculation [18]. 
Table 7. AT mode transmission test.

\begin{tabular}{llllllll}
\hline Test number & interval $(\mathrm{ms})$ & times & secs & Tx (byte) & Rx (byte) & Avg Rx & $\begin{array}{l}\text { receive } \\
\text { Success rate }\end{array}$ \\
\hline 1 & 10 & 100 & 1 & 500 & $500 / 500 / 500$ & 500 & $100 \%$ \\
2 & 10 & 1000 & 10 & 5000 & $652 / 838 / 927$ & 805.6 & $16.1 \%$ \\
3 & 10 & 500 & 5 & 2500 & $652 / 929 / 927$ & 836 & $33.4 \%$ \\
4 & 10 & 250 & 2.5 & 1250 & $932 / 652 / 651$ & 745 & $59.6 \%$ \\
5 & 10 & 120 & 1.2 & 600 & $571 / 562 / 591$ & 574.6 & $95.8 \%$ \\
6 & 20 & 250 & 1 & 250 & $250 / 250 / 250$ & 250 & $100 \%$ \\
7 & 20 & 500 & 2 & 500 & $482 / 480 / 475$ & 479 & $95.8 \%$ \\
8 & 20 & 750 & 2.5 & 750 & $487 / 505 / 480$ & 490.6 & $65.4 \%$ \\
\hline
\end{tabular}

\subsection{Comparison between different transmission methods}

The Digi-developed XBee module has two ways to transmit data: AT mode and API mode. To verify their limits and constraints, we configured the modules using Digi's official software XCTU, tested the abilities to transmit data under both modes, with baud the rate set at 9600 bps in both situations. We found that while transmitting a greater amount of data continuously, API mode tends to be more stable than AT mode.

- AT mode

We connected two XBee modules using XCTU and set them to AT mode (Table 7), set the baud rate at 9600 bps. With the packet size being 5 bytes, we computed the maximum transmission speed to be:

9600 bits $/ \mathrm{sec}=1200$ bytes $/ \mathrm{sec}=240$ packets $/ \mathrm{sec}$

- API mode

We connected two XBee modules using XCTU and set them to API mode (Table 8), and set the baud rate at $9600 \mathrm{bps}$. With the checksum included in the packet in API mode, the size of the packet was 8 bytes, thus we computed the maximum transmission speed to be:

9600 bits $/ \mathrm{sec}=1200$ bytes $/ \mathrm{sec}=150$ packets $/ \mathrm{sec}$

\subsubsection{Fast Fourier Transform(FFT)}

At the initial stage of our research, we collected the acceleration signals and formed a matrix, and conducted one-dimensional discrete Fast Fourier Transform by using the FFT command in MATLAB (n.b. the minimum data amount while conducting the transformation is 1024). The time message was not shown after the transformation, but the value measured in this research represents the natural frequency converted by the change in acceleration of the bridge at steady state. Changes in frequency brought about by a different time block are not within the scope of this research. If we were able to adopt a natural oscillation method or a forced oscillation method, then it would be possible to show the conversion of frequencies from different time, such as Wavelet Transform and Fast Fourier Transform. Yet we found out that the on-site condition is unable to provide a stable wave pattern after running tests on-site, so we adopted Welch method to take measure results from initial, middle and last sections of a long monitoring period into account, as shown in Fig. 3.

\subsubsection{Welch method}

To take measure results from initial, middle and last sections into consideration, we separate the collected raw data into three sections as shown in Fig. 4. After conducting FFT to all sections respectively and take the average of those values, we then obtained the frequency spectrum of the entire section. Furthermore, frequency noise were eliminated in the process of taking average of the three values.

According to the Nyquist-Shannon sampling theorem, while the measured frequency is $\mathrm{N}$, the highest frequency one can get is N/2. When cutting off the measuring of raw data, ARTIFACTS of

Table 8. API mode transmission test.

\begin{tabular}{lllllll}
\hline Test number & interval $(\mathrm{ms})$ & times & $\begin{array}{l}\text { Tx } \\
\text { (packets) }\end{array}$ & $\begin{array}{l}\text { Rx } \\
\text { (packets) }\end{array}$ & $\begin{array}{l}\text { avg Rx } \\
\text { Success rate }\end{array}$ \\
\hline 1 & 10 & 100 & 100 & $100 / 100 / 100$ & 100 & $100 \%$ \\
2 & 7 & 100 & 100 & $100 / 100 / 100$ & 100 & $100 \%$ \\
3 & 6 & 100 & 100 & $100 / 100 / 100$ & 100 & $100 \%$ \\
4 & 10 & 1000 & 1000 & $1000 / 1000 / 1000$ & 1000 & $100 \%$ \\
5 & 7 & 1000 & 1000 & $999 / 1000 / 1000$ & 999.6 & $99.9 \%$ \\
6 & 6 & 1000 & 1000 & $1000 / 999 / 1000$ & 999.6 & $99.9 \%$ \\
\hline
\end{tabular}




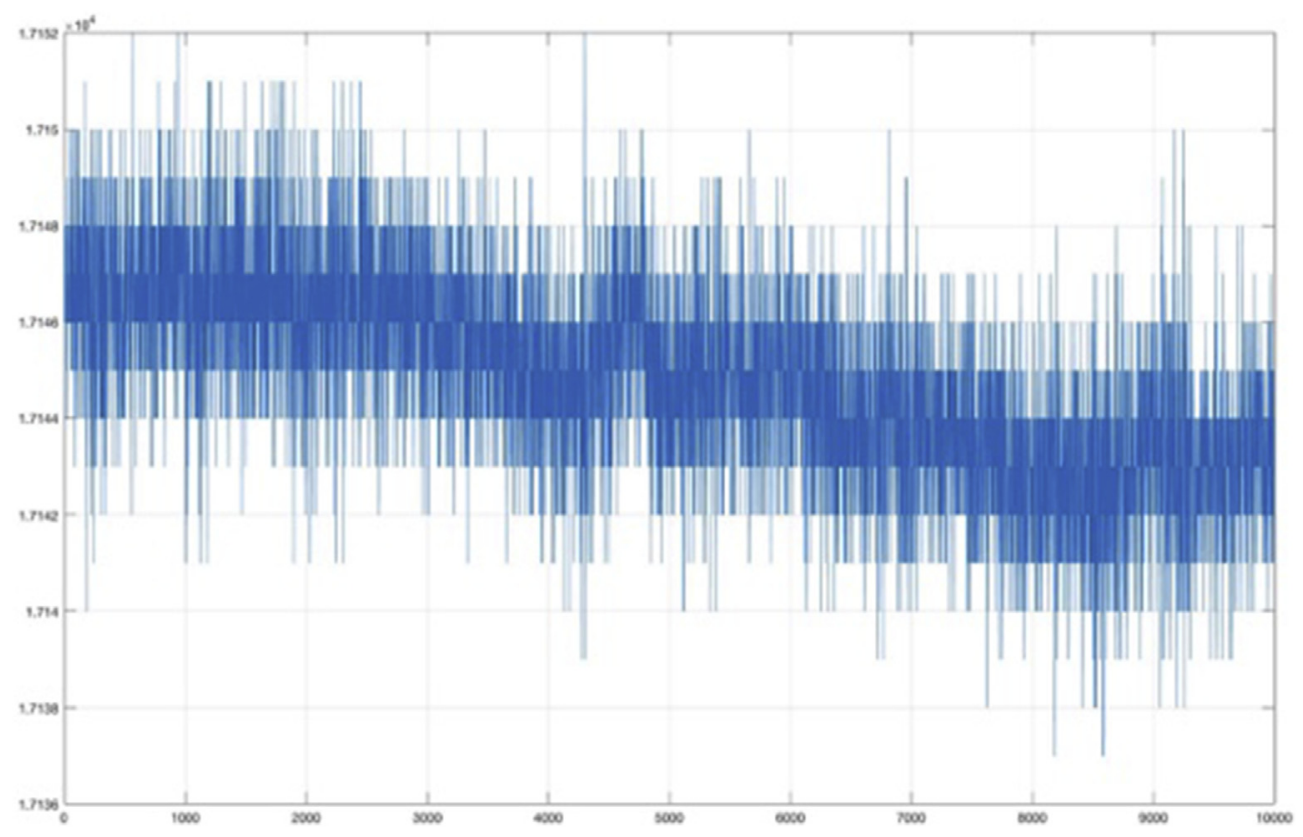

Fig. 3. In-situ test result (original).

limited signal length might occur, which means it might sever an intact frequency section, resulting in abnormal peaks while analyzing the spectrum. As shown in Fig. 5, we utilized a different window function to eradicate this problem. We can see that a window function is a function in which, except for the specified interval, the rest of the values remain at zero. We are able to receive the cut-off data by multiplying the window function by the raw signals.

MATLAB offers various window functions to choose from, Fig. 6 shows three different kinds of window function in terms of their effect.

- Hamming (blue)

- Mainlobe (-3dB) width: 0.039062

- Relative sidelobe attenuation: $-42.5 \mathrm{~dB}$

- Kaiser (orange)

- Mainlobe (-3dB) width: 0.027344

- Relative sidelobe attenuation: $-13.6 \mathrm{~dB}$

- Rectangular (yellow)
- Mainlobe $(-3 \mathrm{~dB})$ width: 0.027344

- Relative sidelobe attenuation: $-13.3 \mathrm{~dB}$

While the Main lobe $(-3 \mathrm{~dB})$ width is wider, more data will be affected by the cutoff. When Relative side lobe attenuation is smaller, the ability to eliminate noise has improved. Taking Rectangular for example, except for the specified interval is value 1 , the rest of it remaining 0 , this is the state before window function is used to cut off the data. Due to a greater amount of onsite noise, this research chose the Hamming window function, which has better ability to eliminate noise.

\subsection{System operation flow}

Research often adopts software packages developed by large companies and patented hardware. Yet to fulfill the spirit of the IEEE.802.15.4 protocol, which includes development at a low cost, a low

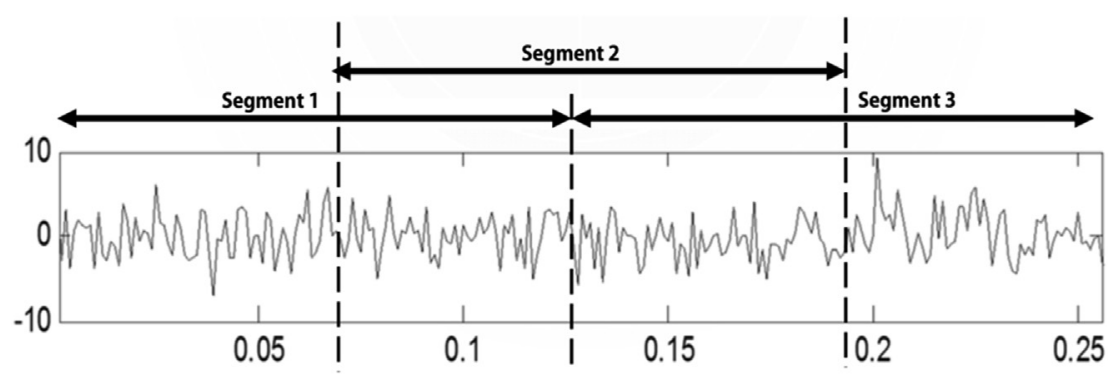

Fig. 4. Welch method segment calculation diagram (http://www.ym.edu.tw/ cflu/CFLu_course.html). 

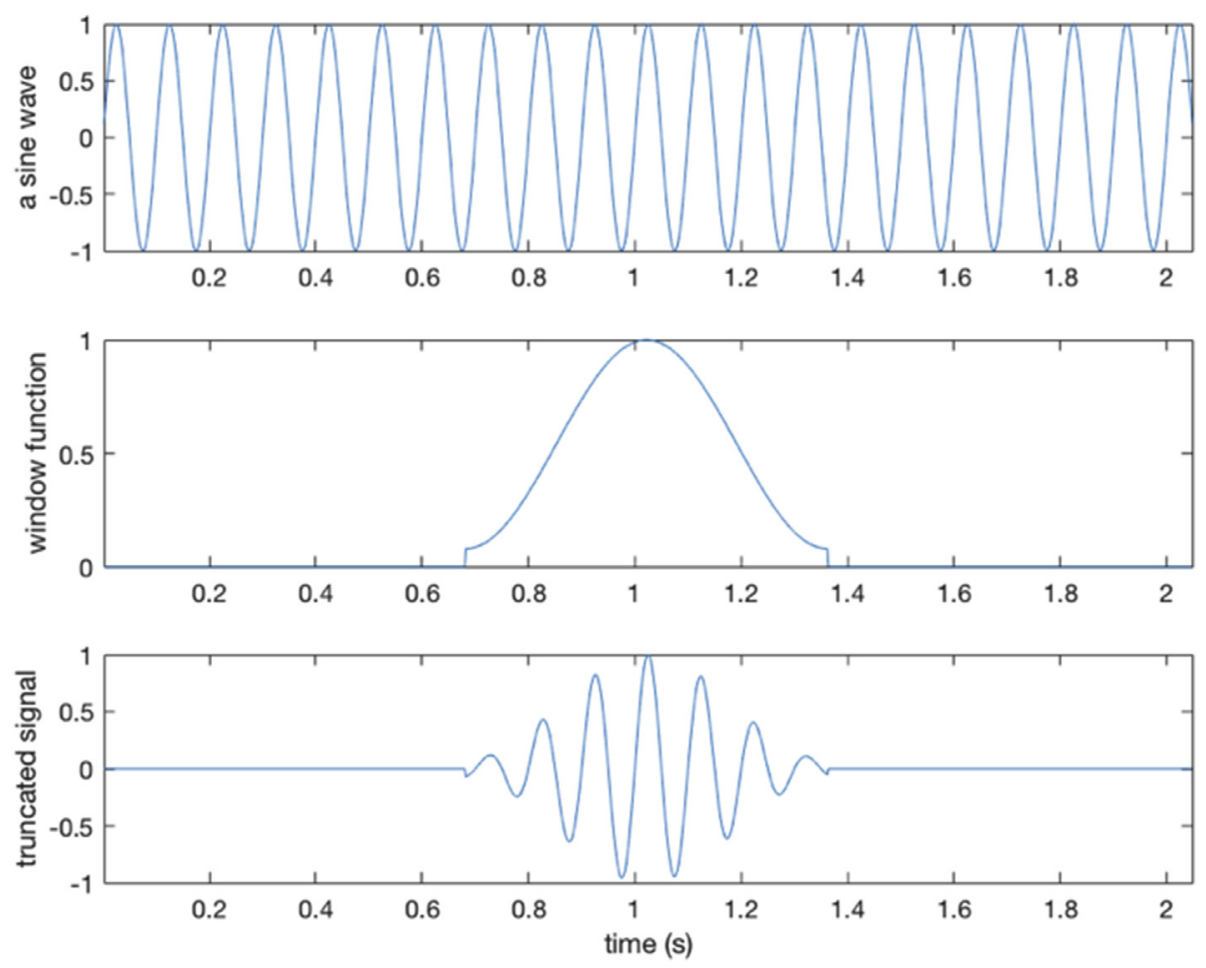

Fig. 5. Window function action diagram.

learning barrier, and high safety, this research utilized open source software and hardware to develop a wireless sensor network and employed the device to measure the natural frequency of bridges, as shown in Fig. 7.

In this research, we integrated WSN, Arduino, 16bit ADC, a SD-2210 accelerometer, and an XBee radio module, as shown in Fig. 8. We tested out different results of using AT and API mode during the development process. The results showed that it is possible to effectively raise the chance of successfully receiving the packet by setting the XBee to API mode. In addition, we compared FFT and its derivative, the Welch method, to see if the latter can receive a better result in spectrum identification.

Lastly, we established a basic sensor network consisting of router, coordinator, and our computer. We drew out the operating flow chart to clarify every situation one might run into at any given stage. The flow chart can also act as a reference for follow-up research, as shown in Fig. 9.

\section{The test of the wireless sensing system}

The test of the wireless sensing system is divided into the indoor calibration experiment and the insitu tests.

\subsection{Selection and introduction of bridge determined}

In the choice of the bridge, considering the accessibility of the study site, this study is based in Taipei City. Eventually, only Yi-Shou Bridge has no vehicle access problems, so the experimental staff has a higher experimental safety, with the measurement point of choice flexibility.

The Yi-Shou Bridge, completed in 1994, located on the Jing-mei River, connects the Hsin-Tien and JingMei districts in Taipei City. It is a 3-span and 2-pier pre-concrete bridge, each span has six $38 \mathrm{~m}$-long PCI beams. The main bridge is $332.5 \mathrm{~m}$ long and 12 $\mathrm{m}$ wide. The Yi-Shou Bridge is an important local pedestrian bridge. The experimental research is shown in Fig. 10.

\subsection{Measurement of transmission distance of wireless sensor system}

The transmission distance of the wireless sensing system will greatly affect the density of the sensor layout. Therefore, based on the results of the test conducted on Zhou-Shan Road at NTU, it was concluded that the XBee can measure a signal accurately within $15 \mathrm{~m}$, while the XBee Pro can measure up to at least $50 \mathrm{~m}$. Since the sampling 


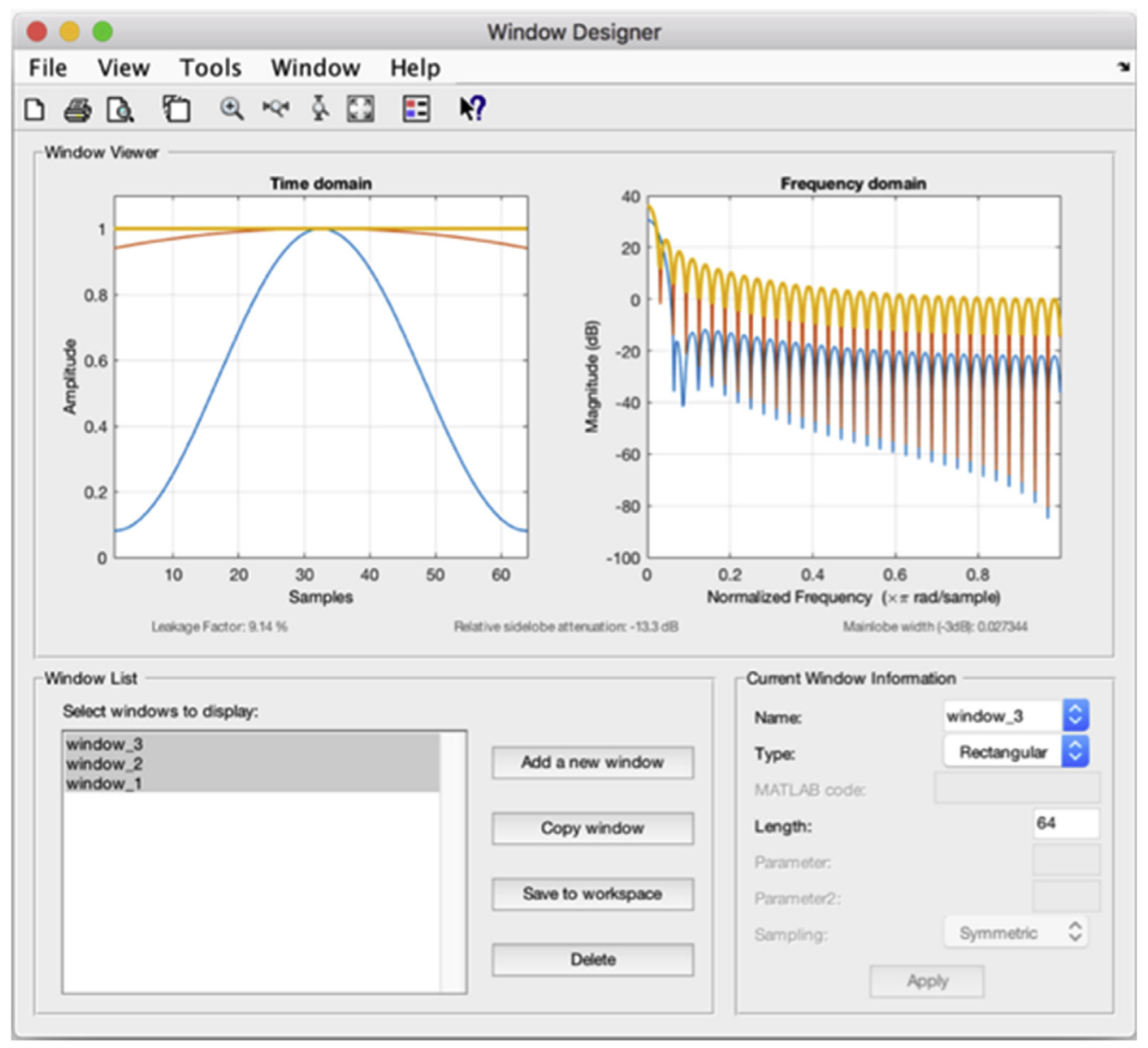

Fig. 6. Window function choose comparison.

frequency is set to $30 \mathrm{~Hz}$, the average packet reception interval is $33 \mathrm{~ms}$. The observation shows that when the time interval of packet reception is more than $50 \mathrm{~ms}$, more than $90 \%$ gets left behind at the same time. The number of packets lost ranges from one to dozens, depending on the length of the delay. The reception rate in distance is shown in Table 9.

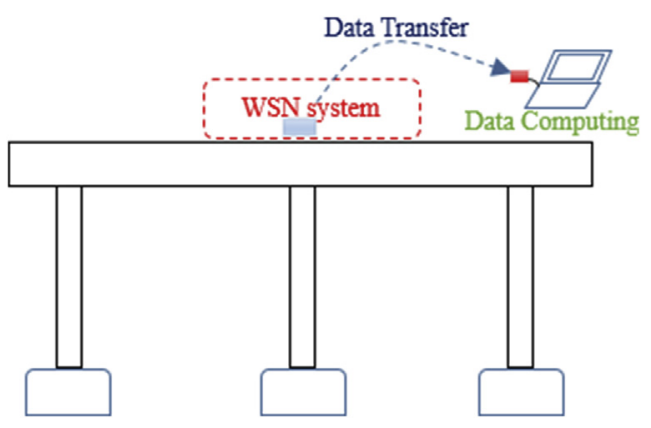

Fig. 7. Bridge piles of WSN scour monitoring system.
4.2.1. Measurement of sampling number of wireless sensor system

In order to specify the minimum sampling number of natural frequency that spectrum instruments are able to identify, in-situ tests measured 1000, $2000,3000,5000$, and 10,000 pieces of data for analysis. The minimum number of analysis required for FFT is 1024, consistent with the results of this experiment, so it could not obtain a spectral peak from the 1000-piece sample. As shown in Table 10, the peak of the spectrum can be identified from the beginning of the 2000-piece sample. Noise is lowest in the 3000-piece sample. From the beginning of the 5000 -piece analysis, it seems that the peak of the second mode appears, but follow-up treatment is still needed. When observing the 10,000-piece sample, it is found that due to the accumulation of energy, there are displacements in the value instrument measured, and it is judged that the signal may be segmented to avoid the shift of spectral peak. 


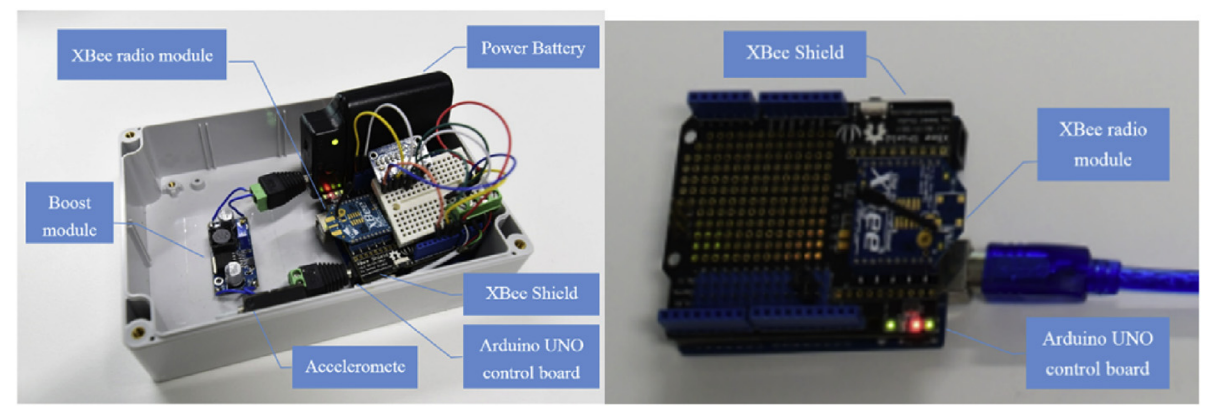

Fig. 8. WSN system devices integration.

\subsubsection{Signal optimization results}

To solve the phenomenon of data offset in the 1000-piece sample of data, this study used the Welch method. The 10,000 pieces of data were cut into three overlapping sections (former, middle, latter), each consisting of 5000 pieces, with the middle section being made of 2500 pieces each of the former and latter. After the application of Fast Fourier Transform (FFT) to each section respectively, an average was taken. This method eliminated the data migration that would have occurred over time. Additionally, the spectrum recognition rate, from the original 13 over 15 identified, could be upgraded to 15 over 15 times. Table 11, shown here, is the experimental spectrum comparison chart.

Using the vibration platform test set up by the structural laboratory at the National Taiwan University Civil Engineering Research Building, the error was less than $5 \%$ in the test time of $60 \mathrm{~s}$, the amplitude was $5 \mathrm{~cm}$, and the test frequency measured from $2 \mathrm{~Hz}$ to $6 \mathrm{~Hz}$. Thus, the system data was identified as consistent with the measured value. In-situ tests took place on Zhou-shan Road at the NTU campus and the Yi-Shou Bridge. The former tests the longest transmission distance of the sensing unit, and the latter tests a total of two subjects. One was to determine the amount of data required for the measurement. Analysis found that the measurement of more than 3000 pieces of data could acquire the more stable results and because the Welch method was used in the study, it is recommended to collect at least 10,000 pieces of data. The purpose of the second test was to determine the difference between FFT and the Welch method in spectrum identification. The results are summarized in Table 12. It is apparent that the Welch method can effectively improve the spectrum recognition rate.

\section{Finite element method modeling}

This research used SAP2000 v.18.0.2 to build the model and modal analysis to compare the natural frequency of the bridge to confirm. Lastly, the dynamic behavior of the bridge was simulated with different scouring depths and different restraint conditions of the soil.

\subsection{Bridge pier modeling}

Bridge Piers are modeled by frame element and the grades of concrete are 3500 psi. According to the design diagram, the size of the cap beam is $11.5 \mathrm{~m}$ (length) $\times 1.8 \mathrm{~m}$ (width) $\times 2.7 \mathrm{~m}$ (height). The models of the cap beam and bridge pier were built separately by the constraints body in order to clarify the relationship of the force between beam and cap beam, but the cap beam and bridge pier are connected in reality. The force in structure analysis was transmitted from point to point, so it was necessary to add a point to make the force transmit from the pre-stressed beam. The total height of bridge Pier including transition region was $14.8 \mathrm{~m}$. The diameter of the circular column was $2.7 \mathrm{~m}$. The height of the circular column was $11.8 \mathrm{~m}$. Transition height was $1 \mathrm{~m}$. Abutment of the bridge was $8.4 \mathrm{~m}$ (length) x $8.4 \mathrm{~m}$ (width) x $2 \mathrm{~m}$ (height), as shown in Fig. 11 .

\subsubsection{Pre-stressed beam modeling}

Pre-stressing does not affect the natural frequency of a structure, so the model can be built by Frame element and the grades of concrete are 5000 psi. There are 6 horizontal pre-stressed beams, and the length of each beam is $19 \mathrm{~m}$. There are $1.9 \mathrm{~m}$ intervals. The section details chart of this research is illustrated in Fig. 12.

\subsubsection{Diaphragm modeling}

Diaphragms are set up between the pre-stressed beams in order to transmit horizontal force. The energy eliminating behavior occurs on the bridge pier instead of the bridge deck. The size of diaphragms is $1.9 \mathrm{~m}$ (length) $\times 0.3 \mathrm{~m}$ (width) $\times 2 \mathrm{~m}$ (height). There are $9 \mathrm{~m}$ and $9.55 \mathrm{~m}$ intervals. 

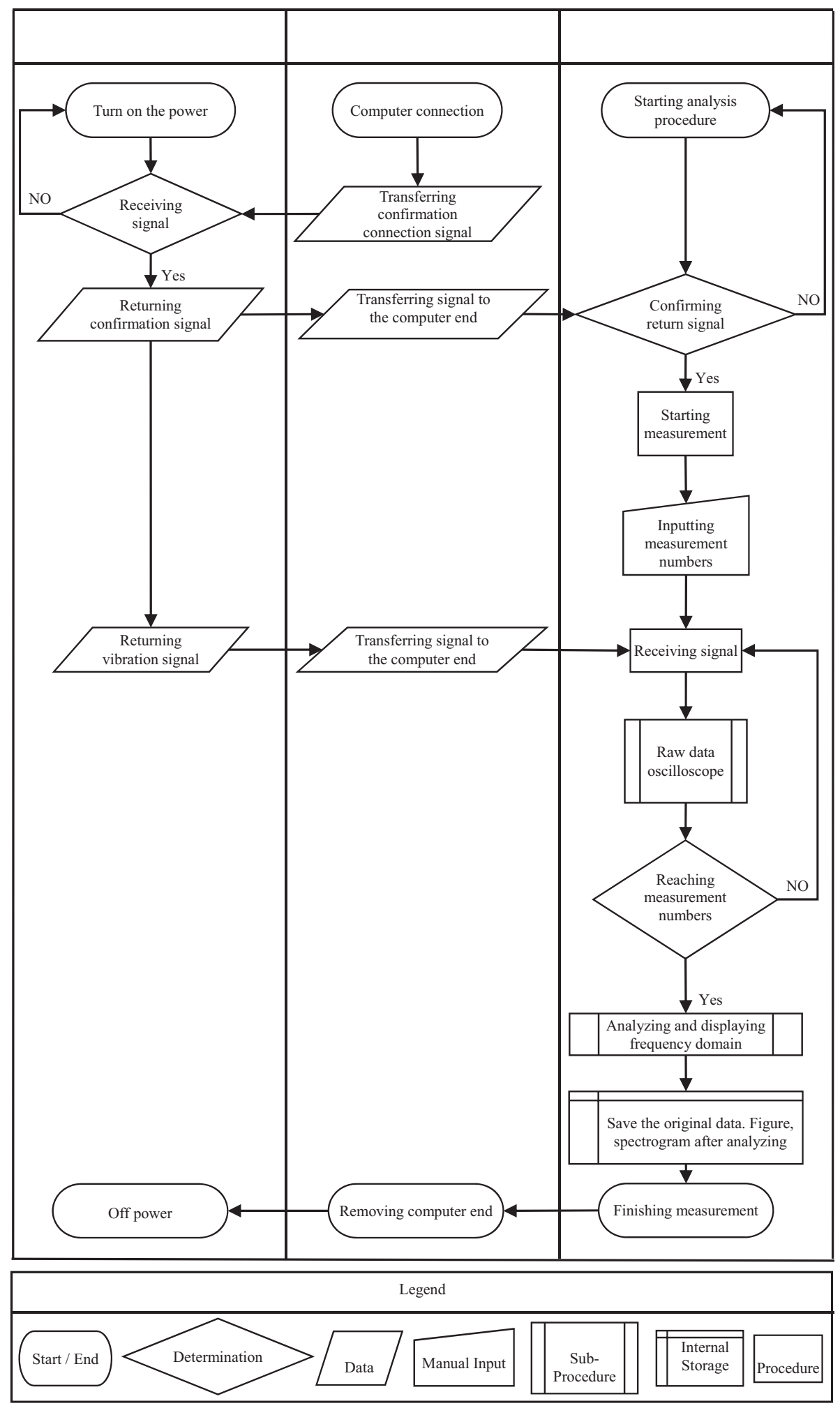

Fig. 9. System operation flow chart. 


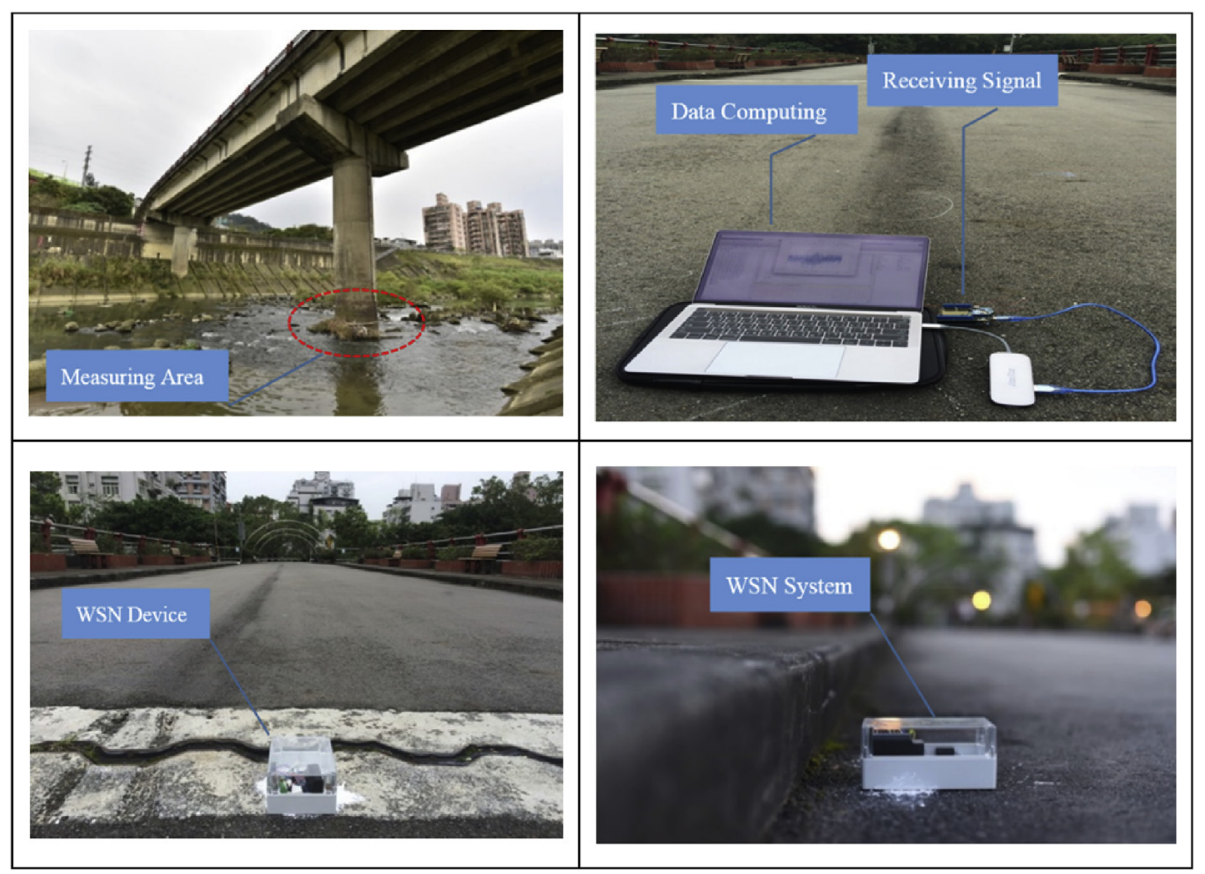

Fig. 10. Yi-Shou bridge experimental research.

\subsubsection{Bridge deck modeling}

If the bridge deck is modeled via SAP2000, the major energy-eliminating behavior occurs on the bridge deck instead of the bridge pier. Therefore, equivalent bracing is used to simulate the bridge deck by frame element, as shown in Fig. 13. Calculations of equivalent bracing are as follows. The calculations are illustrated in Table 13.

$$
\begin{aligned}
& \delta=\gamma h=\tau h / G \\
& \begin{array}{c}
H=\tau t_{w} \gamma \\
\quad \text { So }
\end{array} \\
& \delta=H h / G t_{w} \gamma \\
& \quad \text { and } \\
& D=H d / \lambda \\
& \quad \text { So } \\
& \delta^{\prime}=\left(H / E A_{g}\right) \times(d / \lambda)^{2} \mathrm{~d} \\
& \quad \text { and. } \delta=\delta^{\prime} \\
& \text { So }
\end{aligned}
$$

$$
A_{g}=G / E \times\left(d^{3} / h \lambda\right) t_{w}
$$
where $\mathrm{H}=$ the shear force.

$\mathrm{G}=$ the shear elastic coefficient of the reinforced concrete deck.

$\mathrm{D}=$ the replacement of the material's stress

$\mathrm{d}=$ the replacement of the material's length

$\lambda=$ an interval of cross beam.

$\mathrm{h}=$ an interval of major beam

$\gamma=$ shear strain.

\subsubsection{Foundation pile modeling}

There are 8 foundation piles, each with a diameter of $1.2 \mathrm{~m}$ and depth of $12 \mathrm{~m}$. The arrangement of foundation piles is $3 \times 2 \times 3$ and the grades of concrete are 3500 psi. According to the geological drilling data, cut points are $75,225,375,525,675,825$, $975,1125,1200 \mathrm{~cm}$ underground respectively. The numbers of foundation piles are 8 . The diameter of foundation pile is $1.2 \mathrm{~m}$ and the depth is $12 \mathrm{~m}$.

\subsubsection{Constraint condition of soils}

The constraint condition of soils is simulated by spring. The data from the Standard Penetration Test

Table 9. Transmission distance test.

\begin{tabular}{lllll}
\hline Transmission distance & Packet sent & Packet received & Time delay rate & Reception rate \\
\hline $10 \mathrm{~m}$ & 5000 & 4784 & $98.06 \%$ & $95.68 \%$ \\
$20 \mathrm{~m}$ & 5000 & 4743 & $97.40 \%$ & $94.86 \%$ \\
$50 \mathrm{~m}$ & 5000 & 4049 & $95.66 \%$ & $80.98 \%$ \\
$100 \mathrm{~m}$ & 5000 & 3378 & $92.50 \%$ & $67.56 \%$ \\
$200 \mathrm{~m}$ & 5000 & 3252 & $93.26 \%$ & $65.04 \%$ \\
\hline
\end{tabular}



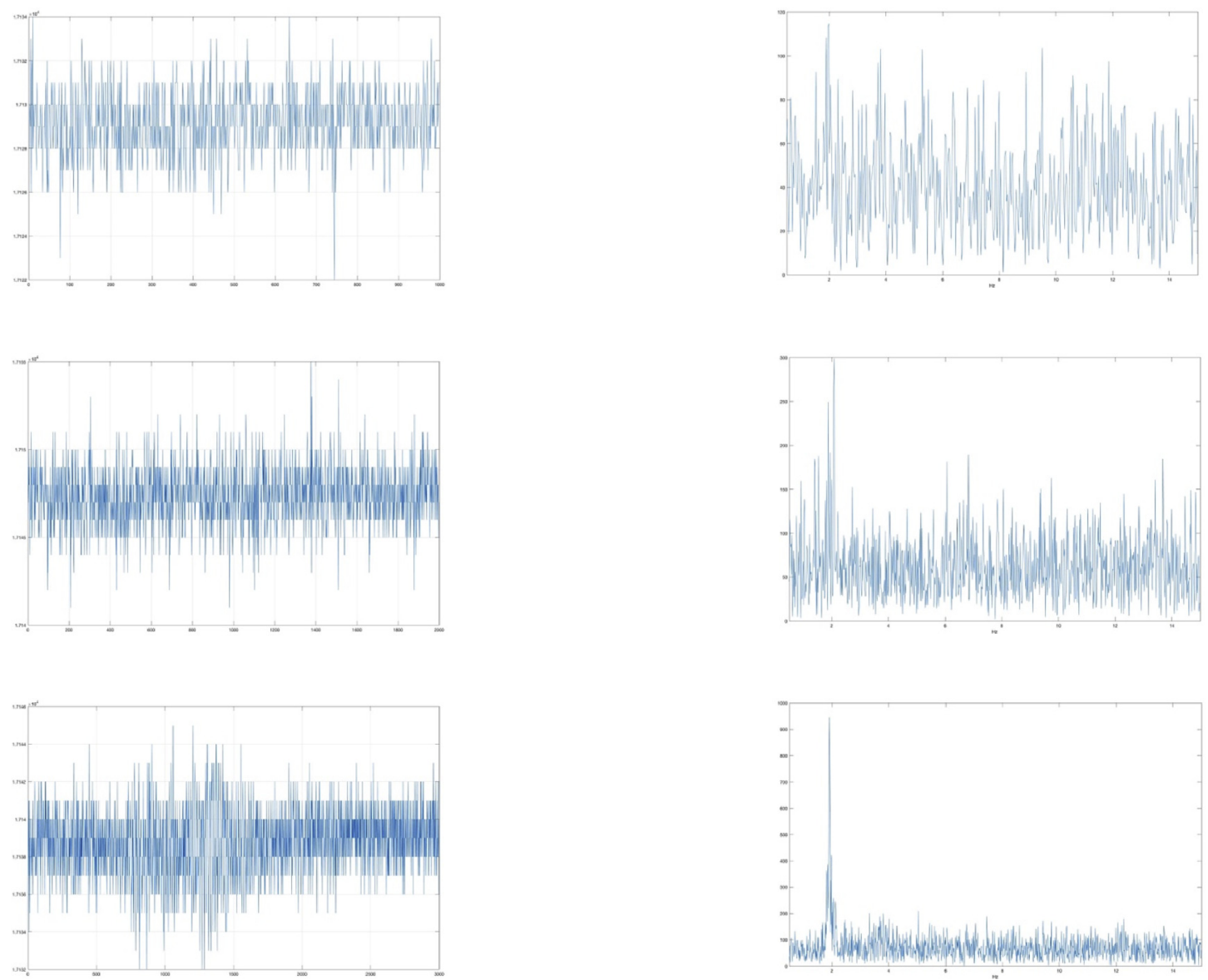

(continued on next page) 
Raw data

FFT Spectrum

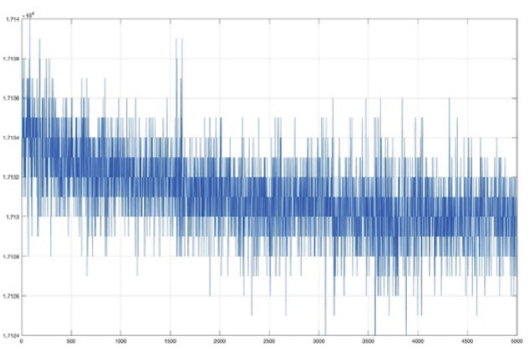

10000

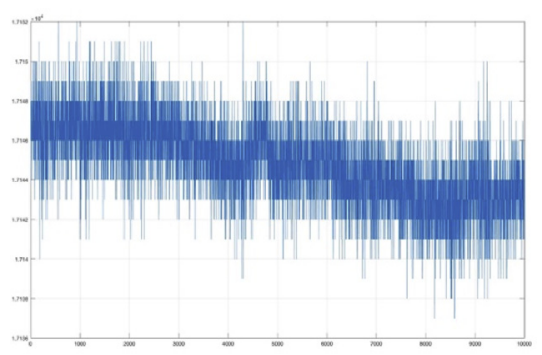


(SPT) is used for getting constraint conditions for the different levels (John, 1983). This study is for reference (JRA, 1996) Calculations of equivalent spring are as follows. The results are illustrated in Table 14. Foundation vertical spring coefficient $\left(\mathrm{kgf} / \mathrm{cm}^{3}\right)$.

$K_{v}=k_{v 0}\left(\frac{B_{v}}{30}\right)^{-\frac{3}{4}}$

Foundation horizontal shear spring coefficient $\left(\mathrm{kgf} / \mathrm{cm}^{3}\right)$

$K_{s}=0.3 K_{v}$

Foundation positive level spring coefficient $\left(\mathrm{kgf} / \mathrm{cm}^{3}\right)$

$K_{H}=\alpha_{k} k_{H 0}\left(\frac{B_{v}}{30}\right)^{-\frac{3}{4}}$ $2 R$

The equivalent width of the bottom area: $B_{V}=$

The area of pneumatic caisson: $R$

Horizontal spring coefficient per unit area: $k_{V 0}$

$k_{V 0}=\frac{1}{30} \alpha E_{0}$

where $\alpha=$ subgrade reaction coefficient $(\alpha=1)$

$E_{0}=$ elasticity coefficient $\left(E_{0}=25 N\right)$

$N=$ Standard Penetration Test of the surface.

$k_{H 0}=$ horizontal spring coefficient per unit area.

\subsubsection{Rubber support pad simulating}

A rubber support pad is simulated by Link and is illustrated in Fig. 14. For the purposes of the simulation, the shear modulus of hardness $60(106 \mathrm{~N} /$ $\mathrm{cm}^{2}$ ) is used, as is shown in Table 15. The Link element will make one side fixed, and the other side is the spring that is connected with the bridge. Vertical direction is simulating by roller, so only the stiffness of the horizontal direction needs to be calculated. The calculation of the spring coefficient of the rubber support pad is as follows.

The stiffness of horizontal direction

$K_{v}=\frac{G \times A}{N \times t}$

Where $\mathrm{A}=$ the area of support pad $\left(\mathrm{cm}^{2}\right)$.

$\mathrm{N}=$ the number of support pad

$\mathrm{t}=$ the thickness of support pad ( $\mathrm{mm})$.

$\mathrm{G}=$ the shear modulus of rubber.

\subsection{Bridge scouring simulation}

After using the flow chart of in Fig. 15 to build the structure model, the maximum spring depth can be regarded as the depth of the scouring, and then the modal analysis method is used to obtain the natural frequency of the various modes of the structure. For the highest coefficient of participation in the first mode of analysis, the results are sorted in Table 16. It can be seen from Fig. 16 that when the scouring depth is deeper, the natural frequency will decrease, so that it can be used as the scouring basis for the evaluation of the bridge.

\subsection{Establishing the standard flow of scouring and natural frequency analysis}

This study used Sap 2000 to build the various components of the bridge structure model, including its set and calculation methods, and used the frame elements to simulate the bridge pier, prebeam, cross-beam, pile, etc. Bridge decks were also simulated by frame elements after calculating the equivalent bracing. The spring element was used to simulate the soil bundling situation. The Link was used to simulate the boundary conditions of the bridge deck extension. Finally, the measured natural frequency of the bridge was used as a benchmark to verify the model and sum up a set of model construction flow charts.

Regarding the bridge scouring simulation, the equivalent soil spring from the button of piles was used to simulate the soil bundling condition, and the effect of water flow on the pier bundle system was neglected. Additionally, the pier scouring depth of different directions was not discussed. The highest point of the spring was regarded as the depth of the scouring. Thus, the relationship between scouring depth and natural frequency of different spring depth could be drawn out, and finally a standard process of scouring and natural frequency analysis was summed up, as shown in Fig. 17.

\section{Conclusion}

To monitor impact of flooding on bridge piers, it is necessary to conduct safety monitoring of bridges. In the performance of this task one deals with problems related to wired transmission methods currently in use, including complexities involved in electronic data transmission pipe installations and the increased cost associated with the increased length of pipes. This study demonstrated that installation of the proposed wireless sensor-based systems on bridge decks is less affected by the recurring typhoons. The proposed solution allows for an efficient installation and use of cheaper and cost-effective sensors for safety monitoring of bridges. This WSN-based solution integrates software and hardware with an accelerator device to conduct a micro-vibration test on the bridge. The following research results have been obtained: 
1. A WSN system was set up using an Arduino UNO board, SD-2210 accelerator, XBee wireless transmission module, and 16-bit digital analog converter. The star-shaped extension was chosen to transmit the signal from a router to a coordinator via an API to continue the follow-up analysis and storage.

2. The receiving interface was initially developed by Tera Term. For stability purposes, it was further developed with the use of MATLAB, a multi-purpose data acquisition, analysis and presentation software environment. This solution was used to visualize waves during testing, to establish results and store data in a csv file, and output the corresponding graph and spectrum. Furthermore, the Welch method demonstrated to improve the resolution of the spectrum in the presented experiment.

3. The bridge structure was simulated by Sap 2000 software environment, using the frame element to simulate the bridge piers, prestressed and horizontal beams, the bridge deck, and pile. Also the spring element is used to simulate soil bundling, and Link to simulate the boundary condition of the extension of the bridge. Finally, the natural frequency acquired from the experiment is used as the benchmark for model verification.

4. As part of scouring simulation, the soil-equivalent spring was used to simulate bridge pier bundling, whereas the impact of water flow and the scouring depth of the piers from different directions were not considered. The maximum soil equivalent spring is set as the point of the maximum scouring depth to establish a process to estimate the scouring depth by determining the natural frequency of pier vibration.

\section{Appendix A. Supplementary data}

Supplementary data to this article can be found online at https://doi.org/10.1016/j.idairyj.2020.104726.

\section{References}

[1] Hsu-Jien. A modified procedure for determining structure frequency of A bri, department of Civil engineering feng Chia University, master's thesis. 2008.
[2] Hong-Yan, Wang. Field scour simulation and dynamic test of a bridge. dept. of Civil \& Environmental Engineering National University of Kaohsiung; 2011. Master's Thesis.

[3] Jian-Yun Chen. Investigation of soil-bridge interaction analyses for bridge scour, department of Civil engineering national Cheng Kung University, master's thesis. 2011.

[4] Chang, Chun-Cheng. A study on the feasibility of identifying the exposure of a bridge pier foundation by using it's natural frequencies, department of Civil engineering national Chiao Tung University. 2012. master's thesis.

[5] Chin-Han Li. A preliminary study of using the pier vibration frequency to evaluate the bridge safety. Dept. of Civil \& Construction Engineering National Taiwan University of Science and Technology; 2012. Master's Thesis.

[6] Yi-Chun Lin. Identification of foundation scour depth using bridge natural frequencies, department of Civil engineering national Cheng Kung University , master's thesis. 2013.

[7] Kaya A. Artificial neural network study of observed pattern of scour depth around bridge piers. Comput Geotech 2010; 37(3):413-8. https://doi.org/10.1016/j.compgeo.2009.10.003 (ISSN:0266-352X).

[8] Prendergast Luke J, Hester D, Gavin K, O'Sullivan JJ. An investigation of the changes in the natural frequency of a pile affected by scour. J Sound Vib 2013;332(25):6685-702. https:// doi.org/10.1016/j.jsv.2013.08.020.

[9] Prendergast LJ, Gavin K. A review of bridge scour monitoring techniques. J Rock Mech Geotech Eng 2014;6(2): 138-49. https://doi.org/10.1016/j.jrmge.2014.01.007.

[10] Chou Jui-Sheng, Pham Anh-Duc. Hybrid computational model for predicting bridge scour depth near piers and abutments. Automat Construct 2014;48:88-96. https:// doi.org/10.1016/j.autcon.2014.08.006.

[11] Kovačič B, Kamnik R, Štrukelj A, Vatin N. Processing of signals produced by strain gauges in testing measurements of the bridges. Procedia Eng 2015;117:795-801. https:// doi.org/10.1016/j.proeng.2015.08.249.

[12] Lin Tzu-Kang, Chang Yu-Shian. Development of a real-time scour monitoring system for bridge safety evaluation. Mech Syst Signal Process 2017;82:503-18. https://doi.org/10.1016/ j.ymssp.2016.05.040.

[13] Bao T, Andrew Swartz R, Vitton S, Sun Y, Zhang C, Liu Z. Critical insights for advanced bridge scour detection using the natural frequency. J Sound Vib 2017;386:116-33. https:// doi.org/10.1016/j.jsv.2016.06.039.

[14] Huang Hai-Bin, Yi Ting-Hua, Li Hong-Nan, Liu Hua. New representative temperature for performance alarming of bridge expansion joints through temperature-displacement relationship. J Bridge Eng 2018;23(7):04018043. https:// doi.org/10.1061/(ASCE)BE.1943-5592.0001258

[15] Mao Q, Mazzotti M, DeVitis J, Braley J, Young C, Sjoblom K, Aktan E, Moon F, Bartoli I. Structural condition assessment of a bridge pier: A case study using experimental modal analysis and finite element model updating. Struct Control Health Monit 2019;26(1):e2273. https://doi.org/10.1002/ stc. 2273.

[16] Creative Commons Corporation. Viewed in. 2016. Arduino, https://www.arduino.cc/. 2017.5.

[17] Texas instruments Incorporated. Viewed in, https://www.ti. com/lit/ds/symlink/ads1115.pdf?ts=1591187458595; 2016.

[18] Silicon designs, Inc. Viewed. https://www.silicondesigns. com/1axis; 2016. 